\title{
Spatiotemporal Evolution and Complexity of Urban Networks in China, 1978-2019: An Enterprise Linkages Perspective
}

\author{
Jiayi Lu, ${ }^{1,2}$ and Dongqi Sun (iD) \\ ${ }^{1}$ Key Laboratory of Regional Sustainable Development Modeling, \\ Institute of Geographic Sciences and Natural Resources Research, CAS, Beijing 100101, China \\ ${ }^{2}$ College of Resources and Environment, University of Chinese Academy of Sciences, Beijing 100049, China
}

Correspondence should be addressed to Dongqi Sun; sundq@igsnrr.ac.cn

Received 22 March 2021; Accepted 20 May 2021; Published 9 June 2021

Academic Editor: Jing-Hu Pan

Copyright (C) 2021 Jiayi Lu and Dongqi Sun. This is an open access article distributed under the Creative Commons Attribution License, which permits unrestricted use, distribution, and reproduction in any medium, provided the original work is properly cited.

\begin{abstract}
With the development of globalization and informatization, the relationships among cities have become closer, and a "network" paradigm in urban studies is gaining attention. To examine China's urban network evolution in a long time series, we used flowbased data to measure enterprise linkages from 1978 to 2019. We investigated the spatiotemporal evolution and complexity characteristics of urban networks in China and arrived at the following conclusions. (1) Intercity enterprise linkages in China have been continuously strengthened. The scale and density of urban networks have increased rapidly. Although the distribution of node cities' importance and influence has been significantly unbalanced, the degree of which has lessened over time. (2) Network density has significantly improved since 1978, gradually forming a monocentric (Beijing) radial pattern. From the beginning of the twenty-first century, the status of core nodes (e.g., Shanghai) has gradually become prominent. Finally, four vertices stood out in 2019 , forming a stable diamond structure. The spatial connection flows of enterprises constituted the core networks with Beijing as the center, skeleton networks with trunk lines formed by subnodes, and regional networks covering a wide range of peripheral areas. (3) China's urban networks were typically small-scale and scale-free. However, the scale-free characteristics were weakened after 2010. The overall scale gap of intercity enterprise linkages gradually narrowed, and the structure of urban networks became optimized. Meanwhile, the urban networks were heterogeneous. There were more cities with headquarter-branches and active investment behaviors, which had strong influence and control over networks, playing their functions of "broker" and "transfer."
\end{abstract}

\section{Introduction}

Since the 1990s, the rapid development of globalization and informatization has deeply influenced and been key in reconstructing the global urban system. The development of any region or city is no longer carried out in a closed system [1-3]. As Sassen, Castells, Derudder, and Taylor have pointed out, cities are increasingly involved in factor flows around the world [4-6], and their importance tends to be determined by their connections with other cities in the world rather than by their absolute size $[7,8]$. Therefore, scholars have turned their attention from urban hierarchies to urban networks, forming a new paradigm that can better explain the structure of urban spatial organization [9].
Urban network research originated from western scholars' research on the network of world city systems. The research comprises three stages: world city, global city, and world city networks. In the 1960s, Hall first put forward a criterion for "world city" from the perspective of urban function [10]. Friedmann then proposed a "world city" hypothesis based on the theory of new international divisions of labor, but his focus remained on cities alone and did not involve measuring their interrelationships [11]. In the early 1990s, under the profound influence of globalization, Sassen proposed the concept of a "global city." She believed that the gathering of advanced producer services in global cities made them develop two core functions, financial centers and headquarters of multinational corporations, 
thus shaping the transnational city networks [4]. At the same time, the acceleration of informatization promoted the emergence of a "network" paradigm based on the complex relationships among cities [5]. Castells believed that the wide application of information network technologies has brought about space-time compression. "Space of flows" has gradually replaced "space of places" as the dominant form of spatial organization [12]. The proposal of "space of flows" provides a solid theoretical basis for the empirical study of world city networks [13]. Based on the work of Sassen and Castells, the Globalization and World Cities Study Group and Network (GaWC) headed by Peter Taylor began to study the influence of spatial organization networks of large enterprises on city regions and on the whole world. Taylor conceptualized the relationships among cities as an "interlocking network model" and considered the subnodal level represented by producer service firms to play a key role in world city networks. The "flows" formed by the global layout of producer service firms stimulated connections among cities and the formation of world city networks [14]. Research on urban systems has gradually turned its perspective from "attribute" to "relationship" and its paradigm from "hierarchies" to "networks" [15].

Today, urban network research has been gaining increased attention. Much research uses microdata, such as enterprise flows, traffic flows, information flows, and knowledge flows, to measure urban networks [16-20]. As economic globalization and regional economic integration continue to spread, the economic connections among cities, as well as intercity enterprise linkages, continue to strengthen [21]. Studies of urban networks from the perspective of enterprise linkages are becoming increasingly prevalent in western urban networks research [22]. There are three main reasons for this: (1) enterprise forms the main body of industry connections and the flows of multielements [23]; (2) enterprise linkage data are easier to obtain than other data and are more generalizable [24]; (3) urban network studies based on enterprise linkages can be applied at almost any spatial scale [22], such as the global scale [6,25], national scale $[26,27]$, regional scale $[28,29]$, and city scale [30]. Representative studies mainly fall into two categories: one is based on advanced producer services (APS) and the other is based on headquarter-branch enterprises.

Urban network research based on APS enterprise linkages is mainly conducted at a global scale and a regional scale. At the global scale, GaWC used distribution data of APS enterprises to build world city networks and analyzed modern service relationships among cities. The findings had a far-reaching impact [31]. At the regional scale, POLYNET led by Peter Hall introduced the perspective of APS enterprise networks to study European urban systems and proposed the concept of a "megacity region" [32]. From then on, scholars have carried out a variety of empirical studies using APS enterprise data. For example, based on GaWC's research on the status of Chinese cities in world city networks, with the latest data from Chinese APS enterprises from 2010 to 2016, Derudder et al. found that the connectivity for all cities in China increased, except for that of Hong Kong, Macao, and Kaohsiung in Taiwan. However, this large-scale connectivity growth was geographically unbalanced [33]. Neal et al. predicted the possibility of 104 APS enterprises in 525 cities in the world expanding, shrinking, or maintaining the status quo and prospectively judged their location selection, thus revealing the transformation trend of world city networks [34]. Although extensive empirical research on urban networks based on APS enterprise linkages has been carried out [35], Krätke suggested that it has ignored the intercity linkages constructed by enterprise in other industries. This is especially with regard to developing countries and newly industrialized countries, where the real economy, e.g., manufacturing industry, is indispensable and should not be excluded. Hence, APS enterprise data alone cannot tell the whole story of urban networks [36].

Urban network research based on headquarter-branch enterprises is represented by the work of Alderson and Beckfield. Based on the location data of the headquarterbranches of 446 industry-wide multinational corporates in 3692 cities, they discussed the centrality of nodes, "coreperiphery" structure, and other network characteristics [37]. They introduced social network analysis into urban network research field, which has been widely used in recent years. For example, Carroll applied social network analysis to study the world city networks formed by board members of the world's top 350 multinational corporations [38]; Pan et al. applied social network analysis to study the cooperation of China's advanced producer service enterprises in the Initial Public Offering (IPO) [39]. Wall and Knaap compared world city networks based on APS enterprises with those based on industry-wide enterprises, employing the distribution data of the headquarterbranches of the world's top 100 multinational corporates in 2259 cities in 2005. In general, urban network research based on headquarter-branch enterprises emphasized the network control of headquarters in global cities over the cities where the branches are located. Focusing on industry-wide enterprise networks can better reflect the panorama of city connections. Therefore, headquarterbranch enterprises have become important in measuring urban network characteristics [40].

Urban network research on China originated from the urban system theories of China put forward by domestic scholars in view of national conditions in the 1980s. "Three structures and one network" proposed by Song and Gu [41, 42], "pole-axis" theory, and "T-shaped" spatial structure strategy proposed by $\mathrm{Lu}$ [43-45] have always played an important role in the planning and development of territorial space and the construction of new urbanization in China [46, 47]. The "network" trend of China's urban spatial structure has been enhanced over time [48]. In this context, the empirical research of China's urban networks from the perspective of enterprise linkages roughly follows that of the western path and has the following main characteristics: the research mainly adopts a single indicator of headquarter-branch enterprises or APS enterprises $[8,49]$, focuses on the main developed urban agglomerations or regions in China [50,51], and selects specific years or short time series $[52,53]$. 
Therefore, compared with Leng et al.'s study using a gravitational method [54] and Wu et al.'s study based on a single year [27], both of which investigated the complexity of urban networks at the national level from an enterprise linkages perspective, we used flow-based data and mixed indicators. We applied GIS, Gephi, Matlab, and other technical means to explore the spatiotemporal evolution and complexity characteristics of Chinese urban networks since the Reform and Opening-Up. With the improved measurement indicators and long time series, we hope to better reflect the evolution and complexity of urban networks at the national scale. This will hopefully provide a scientific reference for the coordinated development of macro city regions and related policy formulation.

\section{Materials and Methods}

2.1. Measurement Indicators. In contrast with traditional measurement of intercity linkages using a gravity model improvement $[55,56]$, we gathered flow-based data to construct China's urban networks, to accurately reflect actual urban network connections [27]. In this study, headquarter-branches and enterprise investment were applied as measurement indicators of enterprise linkages.

2.1.1. Headquarter-Branches. As mentioned earlier, urban network research from an enterprise linkages perspective can be divided into two categories: one is based on APS $[57,58]$ and the other is based on headquarter-branches $[37,59]$. The former has a certain explanatory power with regard to social and economic ties at the global scale, but not enough to truly reflect the actual structure of urban networks at the national scale [60]. Since connections lie in production, sales, supply, capital, and many other aspects between headquarters and branches, cross-regional headquarter-branch enterprises help to reveal the functional ties between cities [61]. Therefore, this article regarded industry-wide headquarter-branch enterprises as "agents" of cities, applying them as a measurement indicator in the study of urban networks in China.

2.1.2. Enterprise Investment. Enterprise investment, especially referring to off-site investment, which is an investment in regions away from the site of the enterprises' main business, is an effective way for enterprises to expand their market and improve the competitive advantages of products [62]. Enterprises choose places to invest after careful strategic analysis. They form association networks, which enable capital and other elements to flow fluently among cities, influencing the structure of urban systems, thus forming an important entry point of studying urban network [63]. In addition to "intraenterprise" organizational connections formed by headquarter-branches, "interenterprise" connections are also considered in enterprises' off-site investment. Therefore, this article not only used the data of headquarter-branches but also used enterprises' off-site investment indicators so as to reveal urban network connections more clearly.
2.2. Research Period. Globalization, marketization, and other factors have been the institutional basis of China's reform and development since 1978 and have profoundly affected the regional economic development pattern of China [64]. Based on this, we investigated the temporal and spatial evolution and complexity characteristics of China's urban networks from 1978 to 2019 and selected five typical years, 1978, 1992, 2001, 2010, and 2019. The reasons for this are as follows: (1) 1978 represents the early stage of China's Reform and Opening-Up, when a highly centralized planned economic system was implemented. In 1992, the goal of establishing a socialist market economic system was made clear, and marketization began to intensify and spread. The period 1978-1992 represents the planned economy period of China. (2) 2001 marked China's accession to the World Trade Organization (WTO) when China took the initiative in meeting the challenge of economic globalization and entered a new stage of opening up to the world. The period 1992-2001 represents the socialist market development period of China. (3) In 2010, to mitigate the impact of the international financial crisis, China accelerated the transformation of economic development, beginning to formulate the "Twelfth Five-Year Plan" for economic restructuring, optimization, and upgrading; thus, 2001-2010 represents the globalization period of China. (4) The period 2010-2019 represents the strategic period of China's economic restructuring and upgrading [65].

2.3. Research Area. We investigated 353 cities in mainland China (including four municipalities directly under central government, 292 prefecture-level cities, nine districts, 30 autonomous prefectures, three leagues, and 15 county-level cities directly under the government of provinces and autonomous regions). The number of cities involved in enterprise linkages has increased year by year (Figure 1 and Table 1). In 1978, only 221 cities established enterprise linkages, accounting for $62.6 \%$ of the total number of cities in the research area. In 1992, the number increased to 349, and the newly added cities were mainly located in Xinjiang, Tibet, Inner Mongolia, and central provinces. In 2001, another two cities were added, Nagqu and Ali in Tibet. In 2010, Kunyu City in Xinjiang was added. Cities involved in enterprise linkages remained unchanged in 2019. So far, only Huyanghe City in Xinjiang has not established enterprise contact with other cities in China (Figure 1).

2.4. Data Processing and Research Methods. Registration data for China's industrial and commercial enterprises in 1978, 1992, 2001, 2010, and 2019 were obtained, and an overlay analysis with 353 municipal administrative divisions in mainland China was carried out in ArcGIS 10.3. Thus, the enterprise database was converted to shapefile data in ArcGIS, and city pairs with enterprise flows in 1978, 1992, 2001, 2010, and 2019 were calculated (Table 1). From 1978 to 2019, the number of pieces of enterprise flows in Chinese cities increased greatly, from 598 in 1978 to 90003 in 2019, almost a 150-fold increase. The processing procedure of the 598, 6985, 27195, 48521, and 90003 enterprise flows in 1978, 


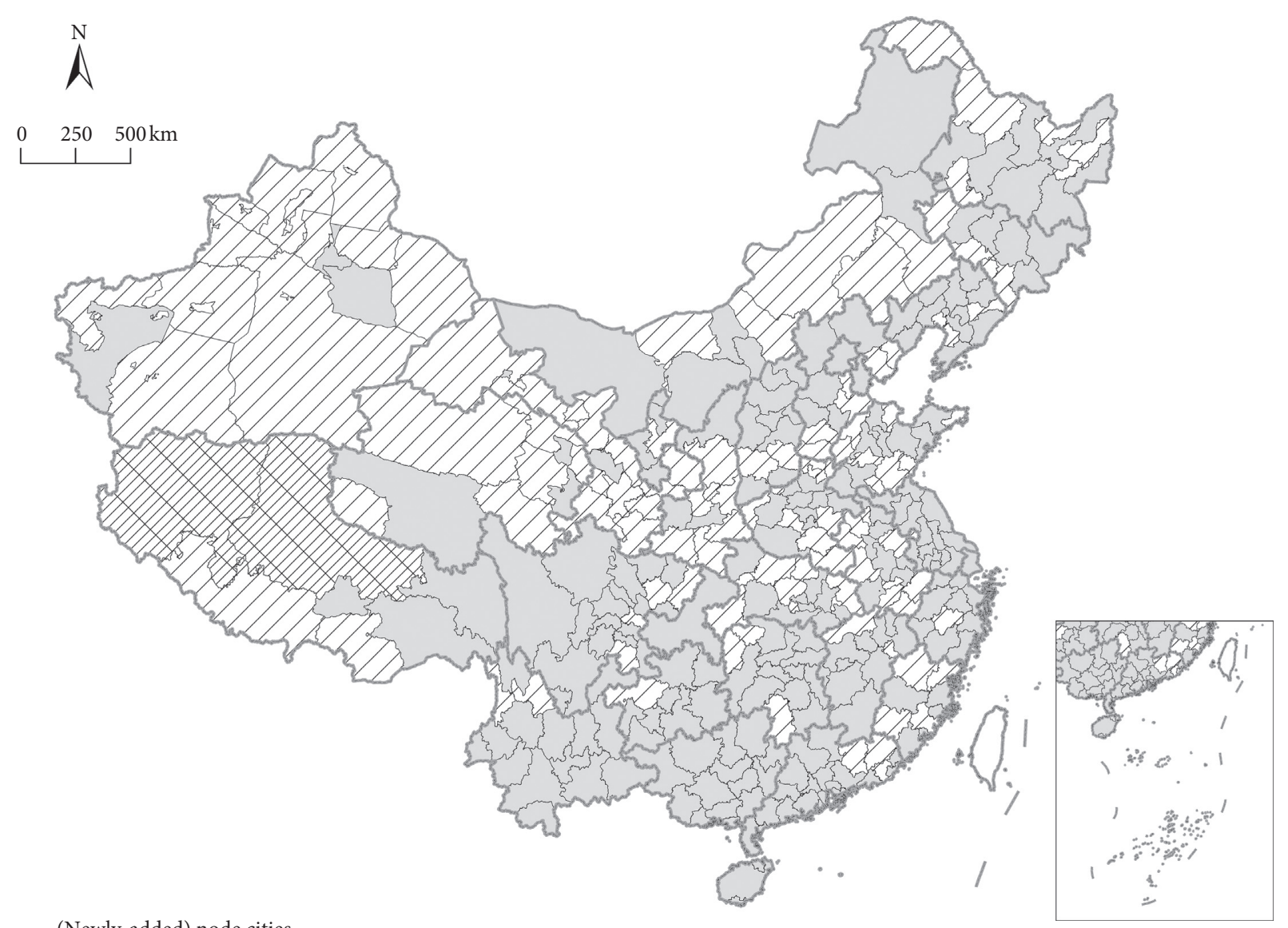

(Newly-added) node cities

Node cities in 1978 (221)
Node cities in 1992 (added 128)

Node cities in 2001 (added 2)

Node cities in 2010 (added 1)

FIGURE 1: Distribution map of (newly added) node cities from 1978 to 2019.

TABLe 1: Basic research data.

\begin{tabular}{cccccc}
\hline \multirow{2}{*}{ Year } & \multicolumn{2}{c}{ City pairs with enterprise flows (unit: pieces) } & \\
& Headquarter-branches & Investor-investee & Total flows before processing & Total flows after processing & Cities involved \\
\hline 1978 & 229 & 369 & 598 & 527 & 221 \\
1992 & 3438 & 3547 & 6985 & 5515 & 349 \\
2001 & 14691 & 12504 & 27195 & 19264 & 351 \\
2010 & 25161 & 23360 & 48521 & 3542 & 352 \\
2019 & 42644 & 47359 & 90003 & 58700 & 352 \\
\hline
\end{tabular}

1992, 2001, 2010, and 2019 is as follows: (1) the research focuses on intercity contacts, so the enterprise linkage samples within a city were eliminated. (2) The number of headquarter-branches and the amount of off-site investment were used as indicators to measure the strengths of intercity linkages. Since they are different in dimensions, we adopted an entropy method to ensure the accuracy and objectivity of the index weight determination; this method is also suitable for double indicators $[66,67]$. Because the entropy method is an objective weighting method based on the degree of data dispersion, and there are natural differences in the degree of data dispersion over the five years, the weights of headquarter-branches and off-site investments may differ. In fact, the weights of headquarter-branches were $0.34,0.32,0.22$,
0.24 , and 0.28 in 1978, 1992, 2001, 2010, and 2019; the weights of off-site investments were $0.66,0.68,0.78,0.76$, and 0.72 , respectively. (3) City pairs with linkage strengths were established, with 527, 5515, 19264, 33542, and 58700 groups of city pairs, respectively. Cities were abstracted as nodes, and the enterprise flows among cities were abstracted as edges to construct directed and weighted urban networks for China.

The study applied a complex network approach to measure and analyze the spatiotemporal evolution and complexity of urban networks in China. Since "networks" are becoming a new form of and new research paradigm for intercity spatial structure, a complex network constructed using the interaction among entities of a complex system 
provides a new means of studying network complexity. In recent years, the complex network approach has been widely used in urban economic network research and has achieved impressive results $[68,69]$. Researchers used complexity theory and tools that directly describe the topology of complex networks, e.g., the degree centrality, average path length, and clustering coefficient, to study the nodes and edges of urban economic networks [27, 70] (Figure 2).

\subsubsection{Degree and Related Centrality Indicators}

(1) Degree, degree distribution, weighted degree, and neighborhood degree: "degree" refers to the number of cities connected to a given city, reflecting the centrality of the city in the network. The larger the value of the degree, the higher the centrality of the city [71]. The calculation formula of degree is as follows:

$$
k_{i}=\sum_{j \in n} a_{i j}
$$

in which $a_{i j}$ is the number of cities $j$ connected to city $i$ and $n$ is the total number of cities in the network. If the number of cities with degree $k$ in the network is $n_{k}$, then the probability distribution $p(k)$ is used to describe the degree distribution in the network:

$$
p(k)=\frac{n_{k}}{n} .
$$

Considering the small scale of some actual networks and the discontinuity of the degree distribution, the cumulative probability distribution $P(k)$ is often used to reduce errors [27]:

$$
P(k)=\sum_{k^{\prime}=k} p\left(k^{\prime}\right) .
$$

In directed networks, the degree can also be divided into "indegree" and "outdegree." The indegree of a city refers to the pieces of flow ending in a city, while the outdegree refers to the pieces of flow starting from a city. In weighted networks, the weighted degree refers to the average weight of intercity flows, i.e., the average strength value of linkages between a city and other cities. The calculation formula is as follows:

$$
S_{i}=\sum_{j \in n} W_{i j} a_{i j}
$$

in which $W_{i j}$ is the weight of the connection edge between cities $i$ and $j$.

Degree correlation analysis is used to describe the matching characteristics of networks. The formula for calculating the neighborhood degree of each node city is as follows [27, 71]:

$$
k_{n n, i}=\frac{1}{k_{i}} \sum_{j \in N_{i}} k_{j}=\frac{1}{k_{i}} \sum_{j=1}^{n} a_{i j} k_{j},
$$

in which $N_{i}$ represents the set of cities connected with city $i$.

(2) Degree centrality, neighborhood centrality, and betweenness centrality are used to measure the centrality of nodes in a network. Neighborhood centrality refers to the sum of the shortest path distances from a given city to other cities, reflecting the relative accessibility of a city in the network. Betweenness centrality refers to the number of shortest paths through a city, which reflects the transit and convergence function of the city in the network [72]. The calculation formulas of degree centrality, neighborhood centrality, and betweenness centrality are described by the following:

$$
\begin{aligned}
& \mathrm{DC}=\frac{1}{n-1} k_{i}, \\
& \mathrm{CC}_{i}=\left[\frac{1}{n-1} \sum_{j=1, j \neq i}^{n} d_{i j}\right]^{-1}, \\
& \mathrm{BC}_{k}=\frac{2}{n^{2}-3 n+2} \sum_{i=1, j \neq k}^{n} \sum_{j \neq k}^{n} \frac{\delta^{k}{ }_{i j}}{\delta_{i j}},
\end{aligned}
$$

where $n$ is the total number of cities in the network, $k_{i}$ is the degree of city $i, \delta_{i j}^{k}$ is the number of shortest paths passing through city $k$ from city $i$ to city $j, \delta_{i j}$ is the number of shortest paths from city $i$ to city $j$, and $d_{i j}$ is the number of the shortest paths between any two cities in the network.

2.4.2. Average Path Length. Average path length refers to the average number of shortest paths between any two cities in the network, which reflects the overall nature of the network [72]. The calculation formula is as follows:

$$
\mathrm{L}=\frac{1}{1 / 2 n(n-1)} \sum_{i>j} d_{i j},
$$

in which $L$ is the average path length, $n$ is the total number of cities in the network, and $d_{i j}$ is the number of shortest paths from city $i$ to city $j$. The smaller $L$ is, the better the connectivity of the network is, and the better the performance and efficiency of the spatial network organization are [72].

2.4.3. Clustering Coefficient. The clustering coefficient is used to measure the degree of network agglomeration, i.e., the closeness between cities and neighboring cities in the network, and reflects the local attribute of the network [72]. The calculation formula is as follows:

$$
C_{i}=\frac{2 E_{i}}{k_{i}\left(k_{i}-1\right)},
$$

in which $C_{i}$ is the clustering coefficient of city $i, E_{i}$ is the actual number of edges between city $i$ and its neighboring cities, and $k_{i}$ is the degree of city $i . C_{i}$ is between 0 and 1 , and 


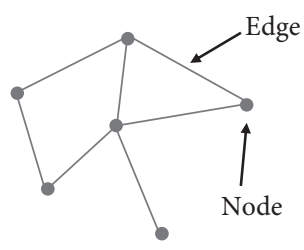

(a)

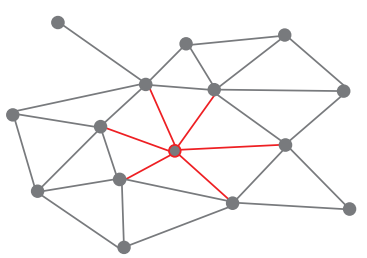

(b)

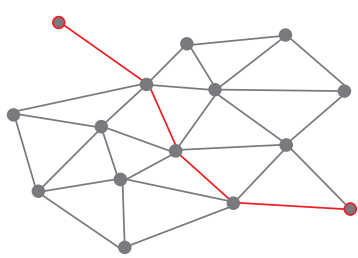

(c)

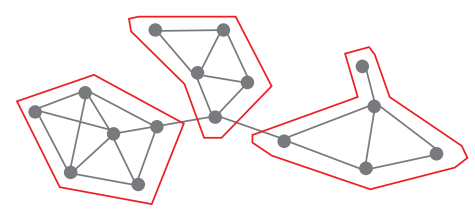

(d)

Figure 2: Models of some statistic tools for complex network topology. (a) Topology. (b) Degree Centrality. (c) Path length. (d) Clustering.

the larger the value of $C_{i}$, the closer the connection between city $i$ and its neighboring cities.

The average clustering coefficient reflects the closeness of cities in the whole network. The calculation formula is as follows:

$$
\mathrm{C}=\frac{1}{n} \sum_{i=1}^{n} C_{i}
$$

in which $C$ is the average clustering coefficient of the network, $C_{i}$ is the clustering coefficient of city $i$, and $n$ is the total number of cities in the network. The larger the value of $C$, the closer the local connections of the whole network.

\section{Spatiotemporal Evolution of Urban Networks in China}

3.1. Topology Evolution of Urban Networks in China. From 1978 to 2019, the scale of China's urban networks expanded rapidly. The number of nodes and edges in the network increased from 211 to 527 in 1978 to 352 and 58700 in 2019, respectively. The network density increased from 0.011 in 1978 to 0.475 in 2019 , and the network diameter decreased from 8 in 1978 to 3 in 2019, indicating that the urban network density of China increased greatly. However, during this process, there were significant differences in the evolution of nodes in China's urban networks (Table 2).

Degree centrality and betweenness centrality reflect the importance and influence of nodes in the network. From 1978 to 2019 , the coefficient of variation of degree centrality remained above 3.3, and the Gini coefficient remained above 0.6. The coefficient of variation of betweenness centrality decreased year by year, but the Gini coefficient also remained above 0.6. This illustrates the discrete and unbalanced distribution of the importance and influence of China's node cities. However, the degree of unbalances has lessened over time.

3.2. Spatial Structure Evolution of Urban Networks in China. Using the ArcGIS spatial analysis platform, the topology of China's urban networks was transformed into spatial connections, whose strengths were divided into four grades. The spatial structure of China's urban networks from 1978 to 2019 is shown in Figure 3. From 1978 to 2019, China's urban networks roughly formed a core diamond structure. The four vertices of the diamond were Beijing (north), Shanghai (east), Guangzhou-Shenzhen (south), and Chengdu (west), which confirmed the findings of Wu et al. [27], Ma et al. [73], and Zhang et al. [74].

The diamond structure was gradually formed in the continuous evolution of the urban networks. In 1978, China's urban networks were relatively sparse. At this time, linkage flows were constrained by distance. Node cities with the highest levels of connection strength were KunmingYuxi (0.665), Beihai-Nanning (0.335), and ChangshaZhuzhou (0.309), all of which were within provincial boundaries. Nanning and Beijing were the most important urban network nodes, and their weighted degrees reached 3.387 and 1.793, respectively, while the values of other cities were below 1 at this time. Nanning gained a high priority in China's node cities. This was mainly due to the "third-line" construction that begun in the mid-1960s, which has led to the formation of a number of industrial cities and bases with military, machinery, and electronics in southwest China. Large- and medium-sized enterprises have formed in these industrial cities [75]. These enterprises have a good industrial base and strong technical force and have established strong enterprise ties with other cities in the province and with important node cities, such as Guangzhou and Beijing.

In 1992, China's urban networks became significantly denser (Table 1) and began to present a monocentric radial pattern. Beijing stood out as the core node of the urban networks and began to focus on developing linkages with cities in the Pearl River Delta, Yangtze River Delta, and Chengdu-Chongqing region, with Beijing-Guangzhou (0.980), Beijing-Shanghai (0.331), and Beijing-Chongqing (0.329) becoming the highest-level linkages.

Since the beginning of the twenty-first century, the linkages in China's urban networks have become gradually closer. In 2001, although the strongest flow in the urban networks was Shenzhen-Haikou (0.788), the core status of Beijing's monocentric radiation remained unchanged, and the southeast and southwest edges of the diamond structure began to strengthen. Shanghai-Guangzhou (0.043) ranked 47th, Shenzhen-Shanghai (0.032) ranked 85th, ShenzhenChengdu (0.028) ranked 105th, and Guangzhou-Chengdu (0.016) ranked 250th in all city linkages in terms of the strength. Notably, the four city pairs did not enter the top 300 city linkages in 1992 in terms of connection strength.

After 2010, Beijing's position as the core node became consolidated. Beijing-Nantong (0.832) has become the strongest flow in China's urban networks, more than three times that of Beijing-Shanghai (0.239), in 2nd place. In 2019, Beijing-Nantong (0.792) and Beijing-Shanghai (0.297) still maintained the highest places in the urban networks in 
TABLE 2: Characteristics statistics of urban networks in China from 1978 to 2019.

\begin{tabular}{|c|c|c|c|c|c|c|}
\hline Statistics & Indicators & 1978 & 1992 & 2001 & 2010 & 2019 \\
\hline \multirow{4}{*}{ Network size } & Number of nodes & 221 & 349 & 351 & 352 & 352 \\
\hline & Number of edges & 527 & 5515 & 19264 & 33542 & 58700 \\
\hline & Density & 0.011 & 0.045 & 0.155 & 0.271 & 0.475 \\
\hline & Diameter & $8(9)$ & $5(9)$ & $4(9)$ & $3(9)$ & $3(9)$ \\
\hline \multirow{4}{*}{ Degree centrality } & Average degree & 2.385 & 15.802 & 54.572 & 95.29 & 166.761 \\
\hline & Average weighted degree & 0.075 & 0.102 & 0.108 & 0.143 & 0.244 \\
\hline & Variable coefficient & 3.640 & 6.858 & 4.583 & 4.536 & 3.303 \\
\hline & Gini coefficient & 0.802 & 0.727 & 0.717 & 0.680 & 0.660 \\
\hline \multirow{3}{*}{ Neighborhood centrality } & $\begin{array}{l}\text { Average neighborhood } \\
\text { centrality }\end{array}$ & 0.257 & 0.420 & 0.535 & 0.587 & 0.678 \\
\hline & Variable coefficient & 0.734 & 0.250 & 0.152 & 0.162 & 0.193 \\
\hline & Gini coefficient & 0.333 & 0.122 & 0.066 & 0.079 & 0.106 \\
\hline \multirow{3}{*}{ Betweenness centrality } & $\begin{array}{l}\text { Average betweenness } \\
\text { centrality }\end{array}$ & 248.439 & 465.900 & 310.164 & 260.264 & 184.247 \\
\hline & Variable coefficient & 5.800 & 5.492 & 3.800 & 2.447 & 1.449 \\
\hline & Gini coefficient & 0.958 & 0.901 & 0.855 & 0.760 & 0.616 \\
\hline \multirow{2}{*}{ Small-world } & Average clustering coefficient & $0.268(0.027)$ & $0.476(0.024)$ & $0.551(0.025)$ & $0.563(0.024)$ & $0.658(0.026)$ \\
\hline & Average path length & $3.645(2.808)$ & $2.382(2.723)$ & $1.891(2.714)$ & $1.741(2.709)$ & $1.525(2.678)$ \\
\hline Scale-free & $\begin{array}{l}\text { Weighted degree distribution } \\
\text { Power law fitting }\end{array}$ & $\begin{array}{c}\mathrm{P}(k)= \\
0.1636 \mathrm{k}^{-2.46} \\
\left(R^{2}=0.9996\right)\end{array}$ & $\begin{array}{c}\mathrm{P}(\mathrm{k})= \\
0.9422 \mathrm{k}^{-1.84} \\
\left(R^{2}=0.9742\right)\end{array}$ & $\begin{array}{c}\mathrm{P}(k)= \\
0.9365 \mathrm{k}^{-1.84} \\
\left(R^{2}=0.9789\right)\end{array}$ & $\begin{array}{c}\mathrm{P}(k)= \\
2.195 \mathrm{k}^{-1.34} \\
\left(R^{2}=0.8074\right)\end{array}$ & $\begin{array}{c}\mathrm{P}(k)= \\
3.051 \mathrm{k}^{-1.02} \\
\left(R^{2}=0.4983\right)\end{array}$ \\
\hline
\end{tabular}

Note. The values in brackets are the statistics of random networks of the same scale.

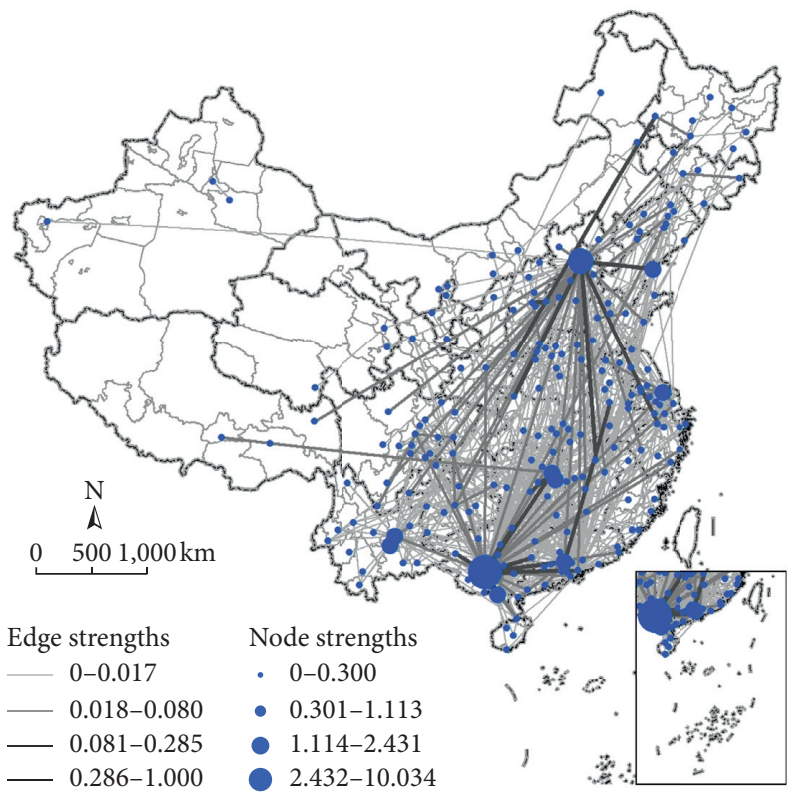

(a)

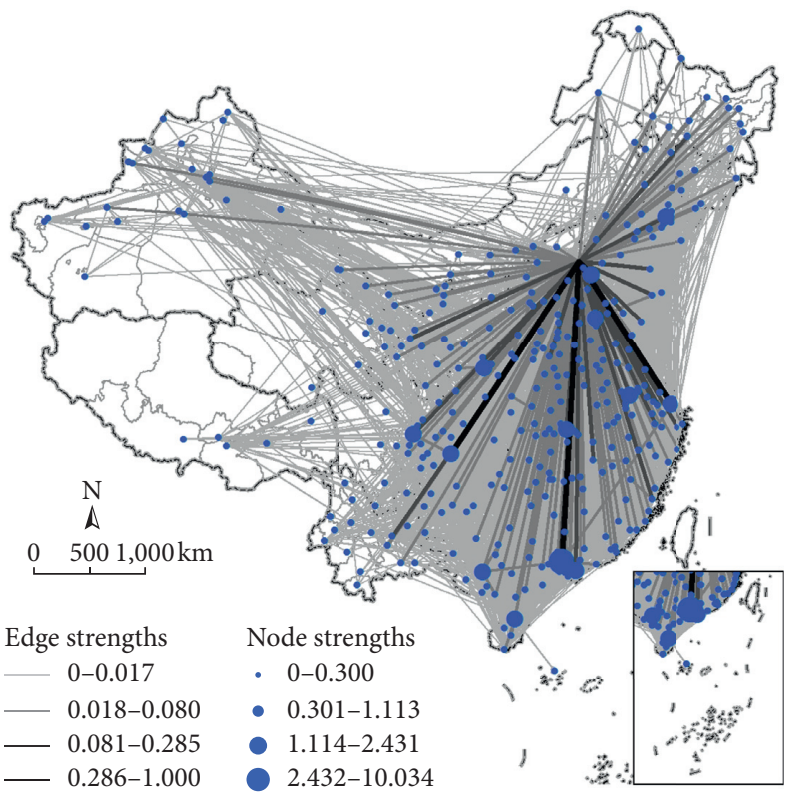

(b)

FIgURE 3: Continued. 


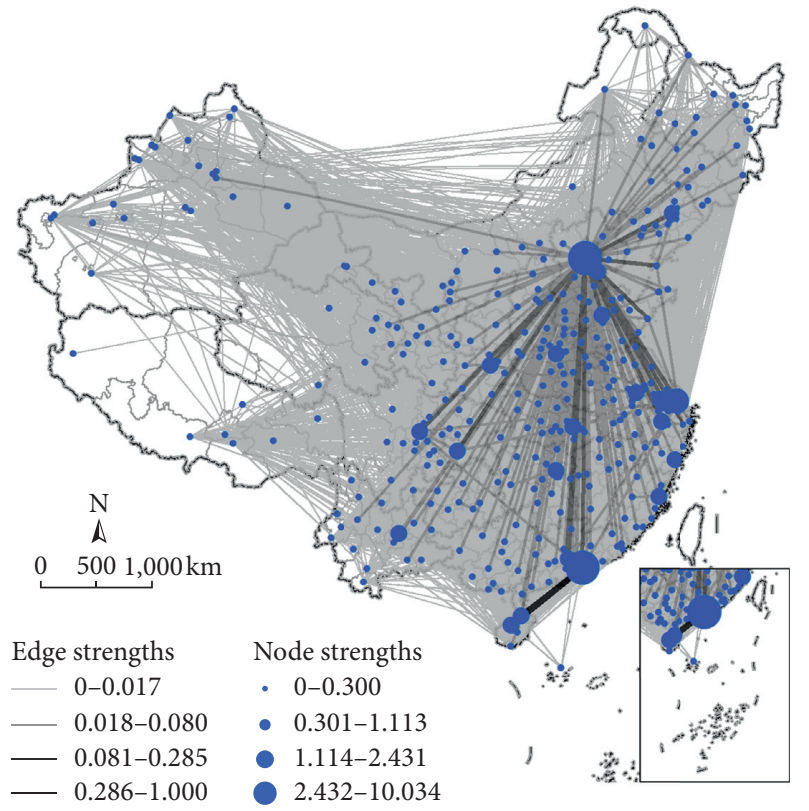

(c)

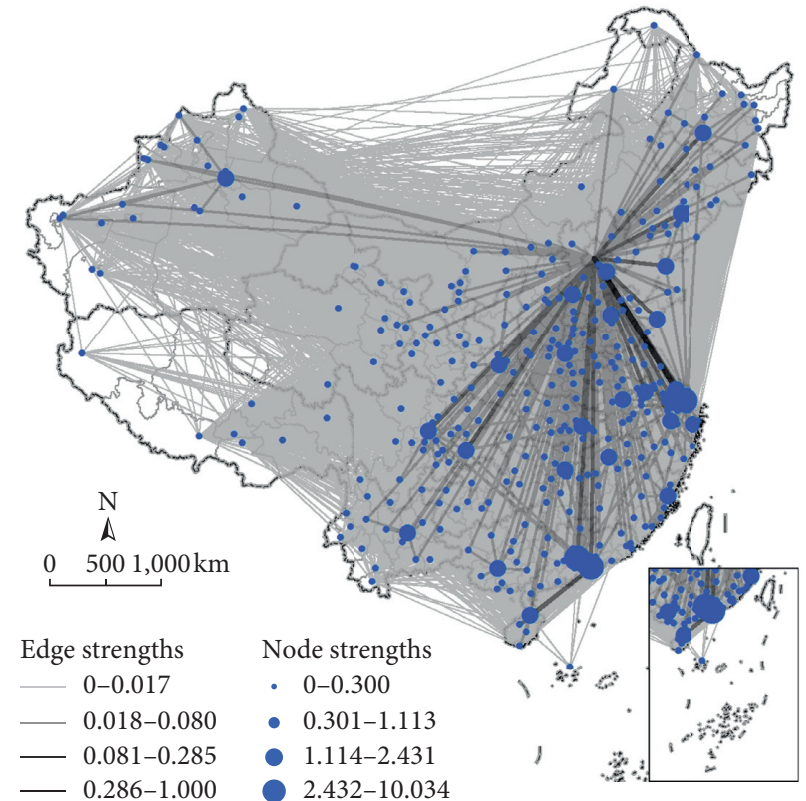

(d)

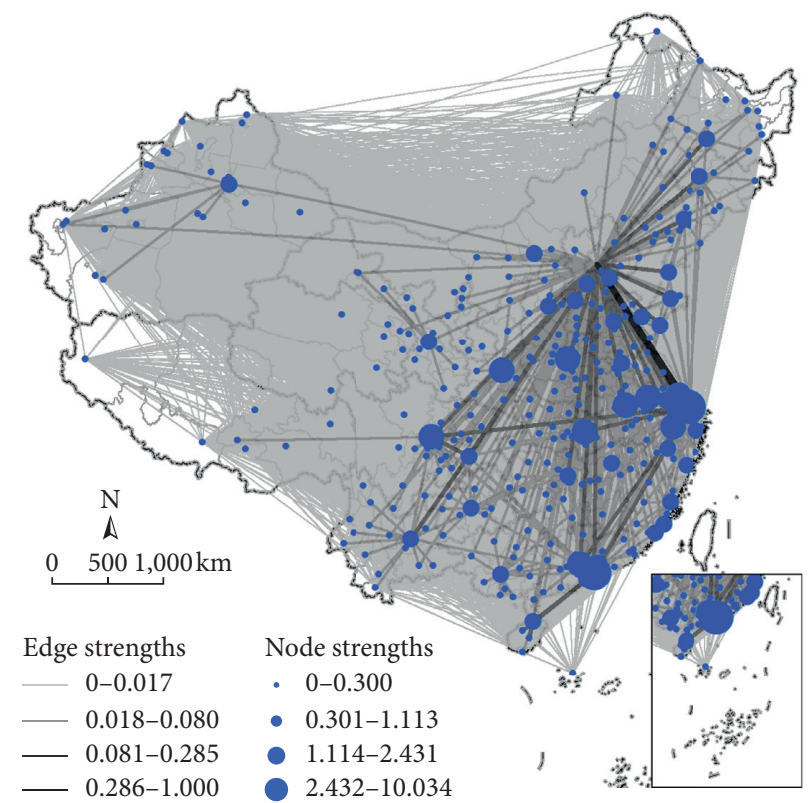

(e)

FIGURE 3: Spatial structure of urban networks in China from 1978 to 2019. (a) 1978; (b) 1992; (c) 2001; (d) 2010 ; (e) 2019.

terms of linkage strength. Hefei-Nanjing (0.391) also ranked among the highest-level flows. At the same time, Shanghai, as one of the vertices of the diamond, strengthened its ties with other important node cities in the network, with Shanghai-Chengdu (0.100) in 36th place, ShenzhenShanghai (0.092) in 42nd place, Shanghai-Wuhan (0.081) in 51st place, and Shanghai-Chongqing (0.0715) in 60th place. Shanghai's core status has gradually become prominent, and the diamond structure of urban networks in China has taken shape.
3.3. Classification of Urban Network Structures in China. To discuss the status quo of China's urban networks in detail, 58700 flows among 352 node cities in 2019 were sorted according to linkage strengths from high to low, and the top $0.1 \%$ o, $0.1 \%$ o. $0.25 \%$ o $0.25 \%$ o $-0.5 \% 0,0.5 \% 0-1 \%$, and $1 \% 0$ flows were extracted using the relevant threshold division method [27, 59] (Figure 4).

The core networks contained six pieces of the top $0.1 \%$ flows, involving core node cities, such as Beijing, Nantong, Hefei, Nanjing, Shanghai, Tianjin, and Chongqing. Beijing- 


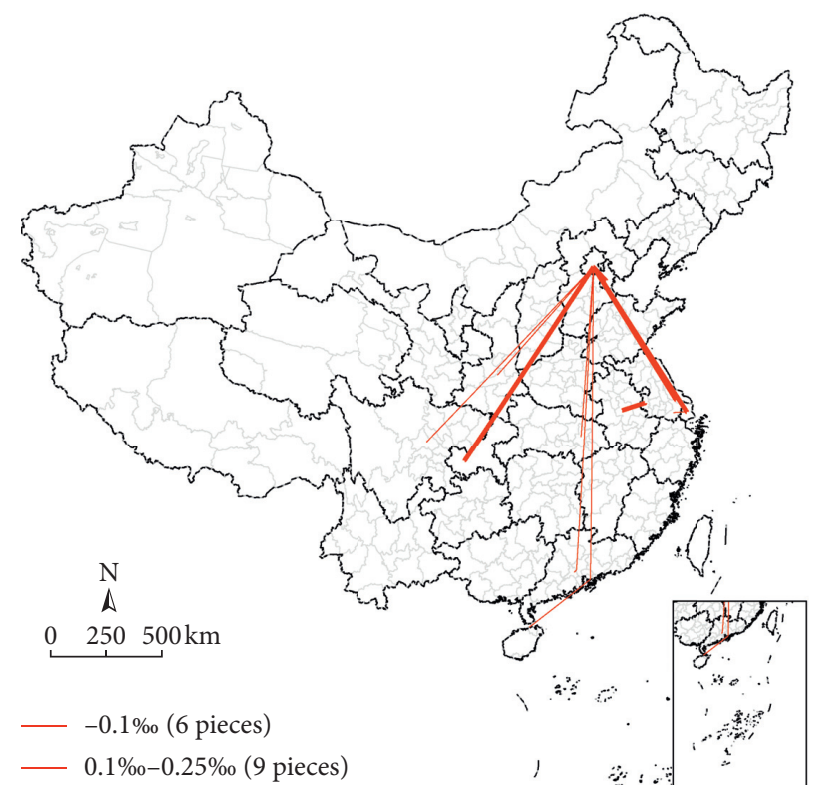

(a)

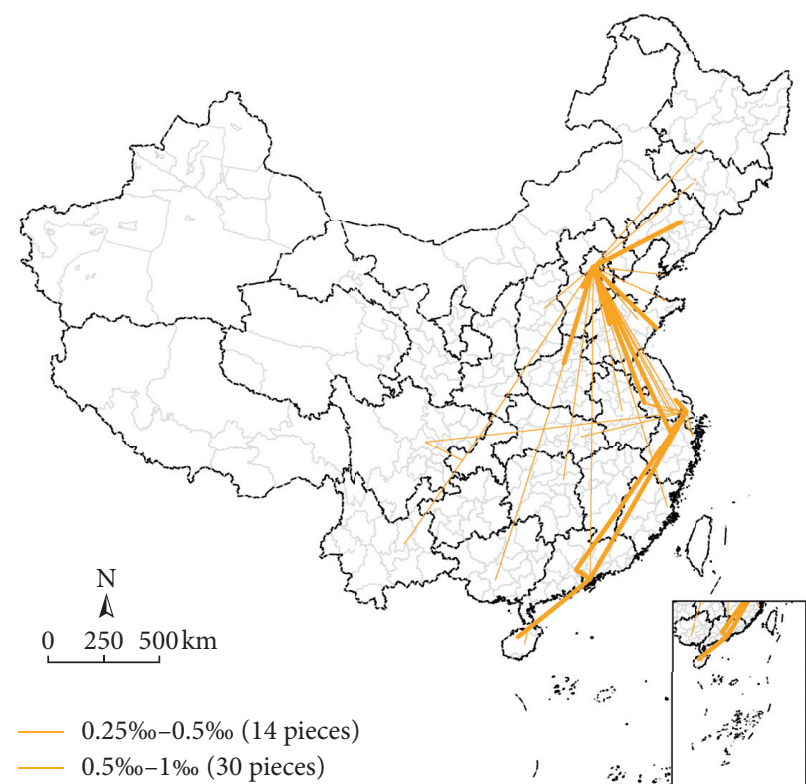

(b)

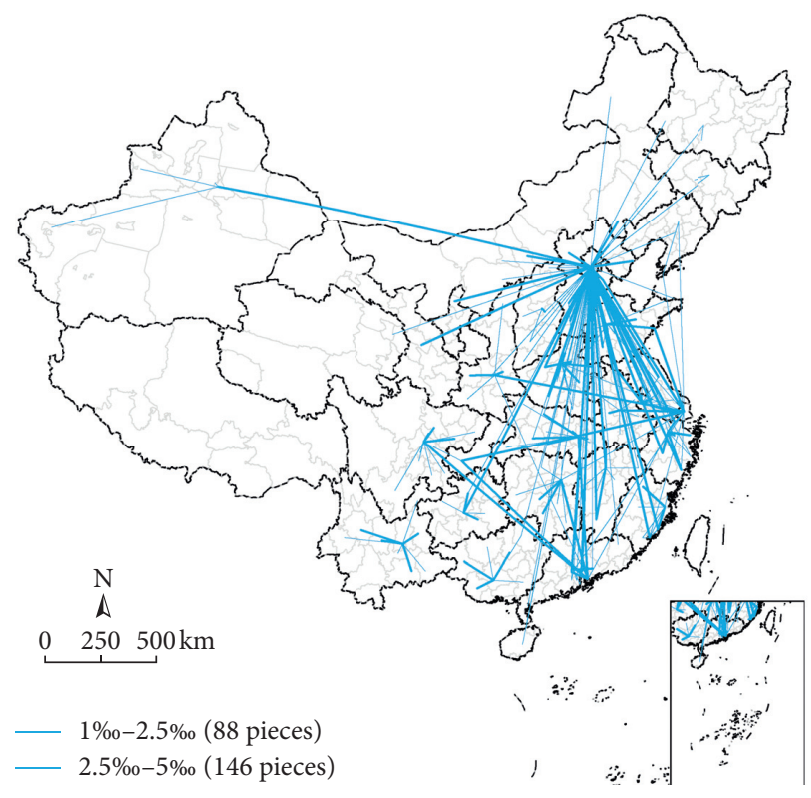

(c)

Figure 4: Three types of urban network structure in 2019. (a) Core networks in 2019. (b) Skeleton networks in 2019. (c) Regional networks in 2019.

Nantong (0.792) ranked first in the whole city network, more than twice the linkage strength of Hefei-Nanjing (0.391), followed by Beijing-Shanghai (0.297), Beijing-Tianjin (0.257), Beijing-Chongqing (0.238), and Shanghai-Beijing $(0.228)$. These six pieces of flow were mainly centered in Beijing, radiating to the Yangtze River Delta and ChengduChongqing region. The weighted outdegree of Beijing (12.710) was nearly four times that of Shanghai (3.296). Beijing has become the most important node city in the networks with an absolute high primacy. There were nine pieces of the top $0.1 \% 0-0.25 \%$ o flows, which started from Beijing, Guangzhou, and Shenzhen and pointed to nine newly added important node cities: Chengdu, Wuhan, Guangzhou, Foshan, Shenzhen, Haikou, Suzhou, Xi'an, and Shijiazhuang. The nine cities were provincial capitals and important cities, located in the central and western regions of China and in the southeast coastal areas, which constituted the diamond structure of the urban networks.

The skeleton networks contained 14 pieces of the top $0.25 \%-0.5 \%$ flows. Besides 16 important node cities in the core networks, Danzhou, Hangzhou, Jinan, Qingdao, Zhengzhou, Baoding, and Shenyang were added to the important node cities. Cities in the Bohai Rim-Yangtze River Delta and in the Yangtze River Delta-Pearl River Delta were 
closely connected, forming the right half of the diamond structure. There were 30 pieces of the top $0.5 \%$ - $1 \%$ o flows. Dongguan, Changsha, Dalian, Harbin, and other cities entered the skeleton networks, and the subnodal linkages in the diamond structure were enhanced.

The regional networks included the top $1 \%-2.5 \%$ and $2.5 \%-5 \%$ flows, which increased by 88 and 146 pieces of flows, respectively, compared with the core and skeleton networks. Except for Tibet, all provinces in mainland China participated in the regional networks, which covered a wide area in China. Compared with core networks and skeleton networks, the diamond structure of regional networks expanded to the peripheral regions in the northeast, northwest, and southwest of China. Connections between node cities and the capital cities in the peripheral regions have strengthened. After sorting the weighted indegree of nodes from high to low, Kunming (0.331), Shenyang (0.322), and Urumqi (0.201) ranked 25th, 26th, and 46th among 352 node cities in China, respectively, becoming subnodes in the urban networks. Subnodes focused on developing connections with neighboring cities. For example, the top 15 flows starting from Kunming were all connected with cities within Yunnan Province, among which seven pieces entered the top $1 \%-5 \%$ flows in the regional networks.

\section{Complexity Analysis of Urban Networks in China}

4.1. Small-World and Scale-Free Urban Networks in China. The average path lengths of China's urban networks ranged from 1.525 to 3.645 from 1978 to 2019 and decreased year by year. Except for 1978, the values of average path lengths were slightly lower than the theoretical values of the average path lengths for random networks of the same scale. The clustering coefficients ranged from 0.268 to 0.658 and increased year by year, which were much higher than the theoretical values (Table 1). The average path lengths of China's urban networks were relatively short, while the clustering coefficients were relatively high, indicating the typical small-world characteristics of the network.

The distribution of the weighted degree of the urban networks followed a typical "long-tail distribution" (Figure 5), which was fitted by a power law-the goodness of fit remained above 0.97, illustrating that a large number of nodes had a small degree; only a few nodes were large nodes. The network showed a polarization trend and had significant scale-free network characteristics. In 2010, the goodness of fit decreased to 0.807 , while in 2019 , it was only 0.498 , indicating that the scale-free characteristics of China's urban networks gradually weakened. The gap of intercity enterprise linkages narrowed. The excessive concentration of headquarter-branches and investment power in some cities was alleviated, and the structure of urban networks became optimized.

4.2. The Correlation of Urban Networks in China. The degree distribution reflects the probability of different values of node degree in a network. However, even networks with the same degree distribution may show different properties or behaviors because internode correlation is important and requires consideration. Thus, we further explored the structural characteristics of China's urban networks using correlation analysis. The results showed that 1978-2010 had similar correlation characteristics to those of 2019. Due to space limitations, only a correlation analysis of 2019 is presented here. The results for other years will not be described in this article.

Firstly, we investigated the degree-degree correlation of the network, which describes the joint probability of node degree at both ends of an edge randomly selected in a network. If the node degree at both ends of an edge is completely random, whether or not there is a connected edge has nothing to do with the degree values of the two associated nodes, meaning the network does not have degree correlation. Otherwise, the network has degree correlation. If the overall network is positively correlated (a "homology network"), this means that large nodes in the network are more inclined to connect with similar nodes. In contrast, the network is negatively correlated (a "heterogeneous network") [76].

Using equation (5), the average neighborhood centrality of the network was calculated. Correlation analysis between the average neighborhood centrality and node degree showed a significant negative correlation, with a correlation coefficient of -0.921 (Figure 6(a)). This indicates that the larger the degree of the node, the smaller the average degree of its connected nodes, meaning the whole network connection is heterogeneous. In China's urban networks, Beijing, Shanghai, Shenzhen, and Guangzhou, which were of high degree, had enterprise linkages with most node cities. The degree distribution showed that the degree values of most nodes in the network were quite small, which made the cities connected with those important ones such as Beijing and Shanghai, not only large in quantity but small in average degree value. The average neighborhood degrees of Beijing (212.766), Shanghai (212.766), Shenzhen (213.271), and Guangzhou (215.713) were all lower than the average value of the network (243.850). On the other hand, although Sansha City in Hainan, Hainan Tibetan Autonomous Prefecture in Qinghai, and Tumushuke City in Xinjiang are located in remote areas, cities which had their corresponding headquarters and investors were generally the above-mentioned cities with higher degrees, such as Beijing, Shanghai, Guangzhou, and Shenzhen, making these remote cities higher in average neighborhood degree, despite these cities' own degrees not being high. In addition, the correlation coefficient between degree and weighted degree was 0.423 , showing a significant positive but nonlinear correlation (Figure 6(b)). The nodes with small degrees grew slowly in weighted degree. With increasing node degree, the weighted degree increased more significantly. When both the degree and weighted degree of the nodes were converted into the double logarithm, a positive linear correlation was obvious, with a correlation coefficient of 0.915 . This indicates that the relationship between degree and weighted degree generally obeyed a power law. 


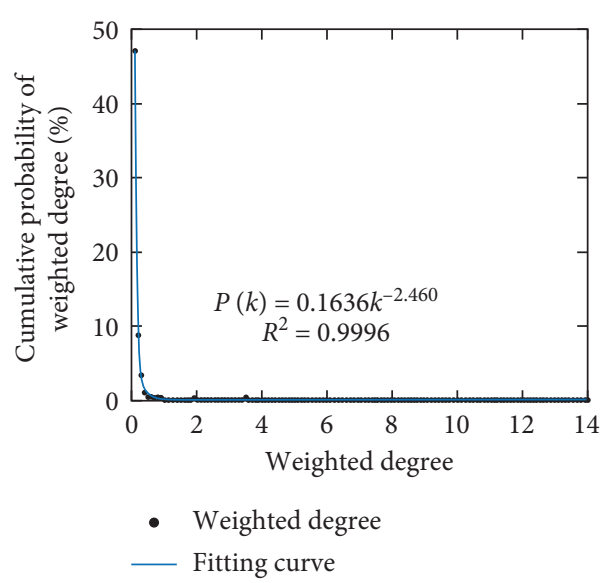

(a)

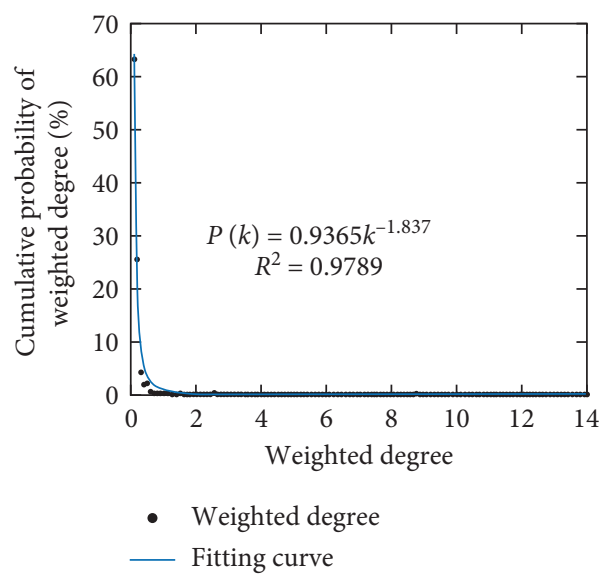

(c)

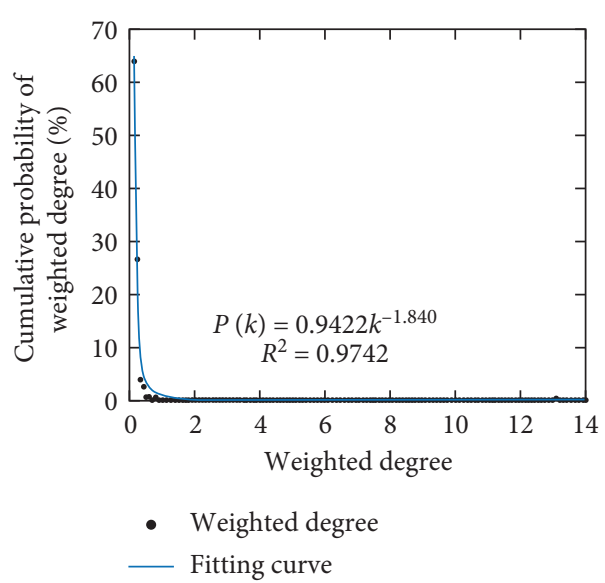

(b)

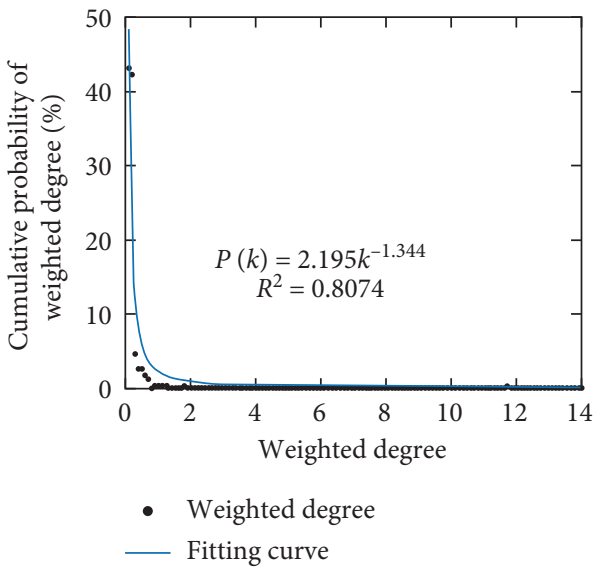

(d)

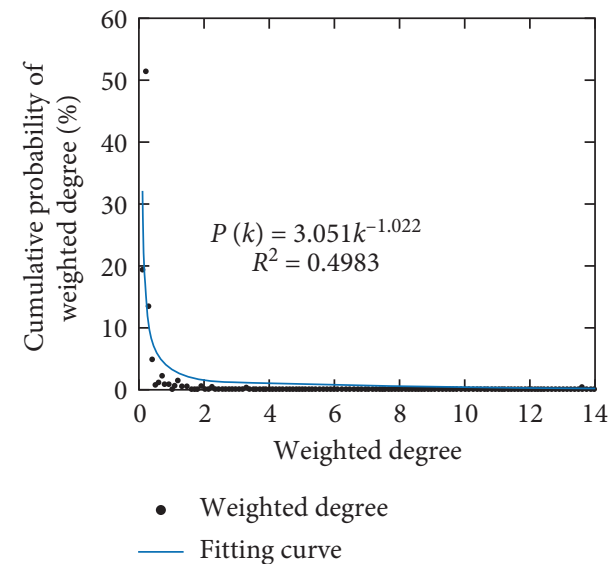

(e)

Figure 5: Cumulative probability of weighted degree of urban networks in China from 1978 to 2019. (a) 1978; (b) 1992; (c) 2001; (d) 2010; (e) 2019 .

The relationship between degree and clustering coefficient is called the "cluster-degree correlation," which is also an important aspect of network structure. If there is an approximate relationship $\mathrm{C}(\mathrm{k}) \sim \mathrm{k}^{-1}$ between the clustering coefficient and node degree, then the network is hierarchical [27]. In China's urban networks, the correlation coefficient between node degree and clustering coefficient was -0.946 , showing a significant negative correlation (Figure 6(c)). We found that when the degree value was less than 300 , the negative cluster-degree correlation was not significant; otherwise, the negative correlation was significant. Because low-value nodes tended to be connected with high-degree nodes in heterogeneous networks, the connections among the latter were high; thus, low-value nodes presented high- 


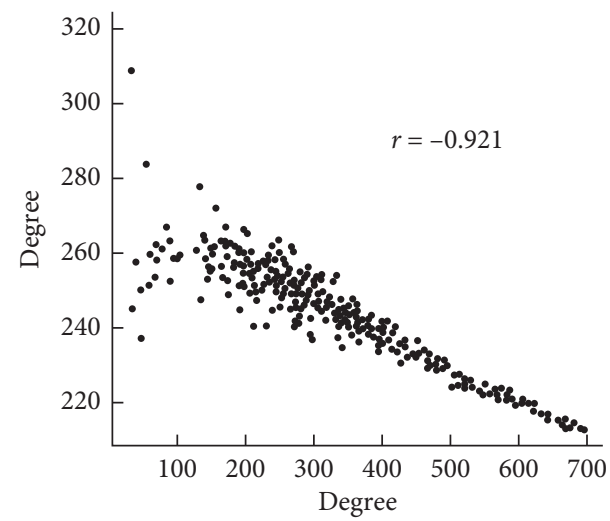

(a)

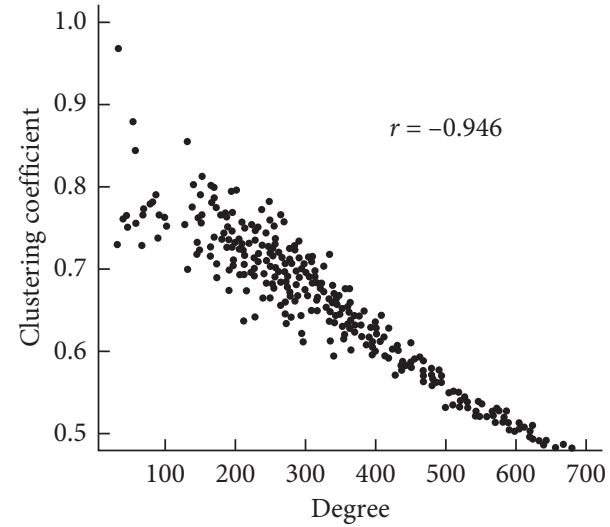

(c)

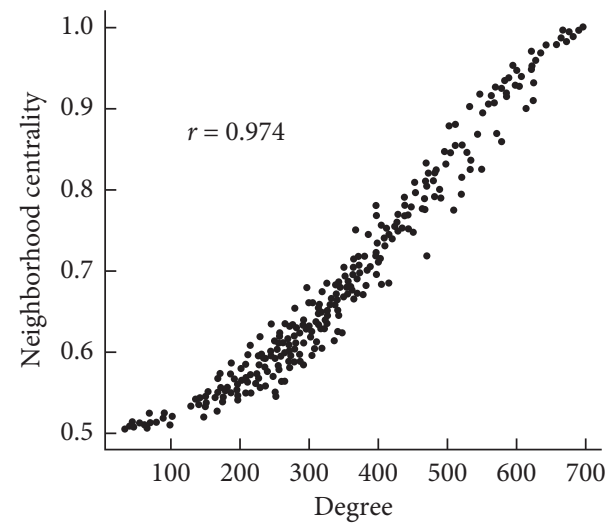

(e)

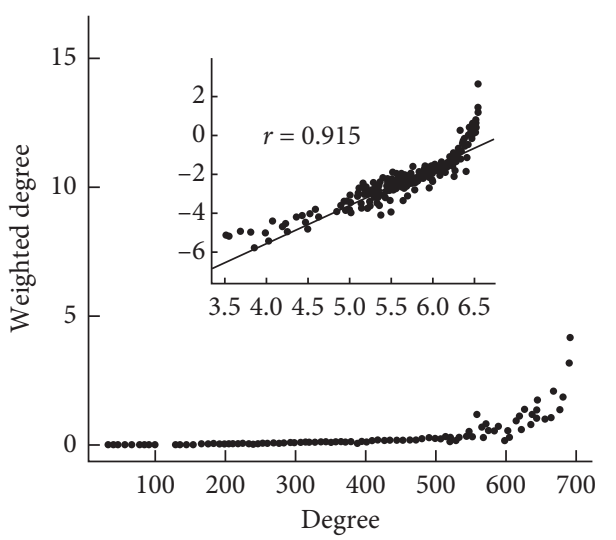

(b)

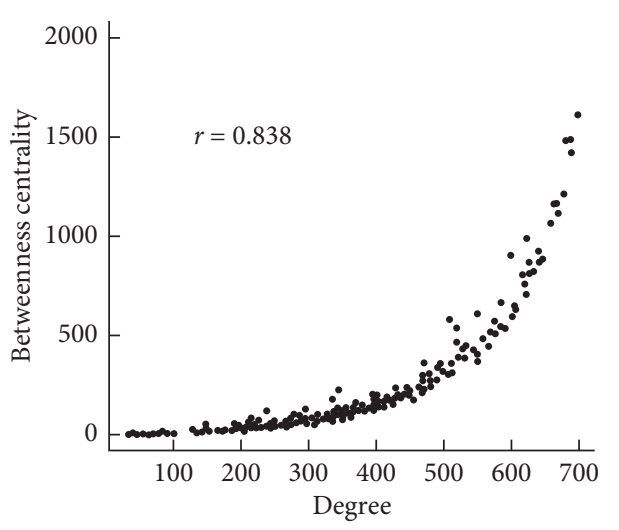

(d)

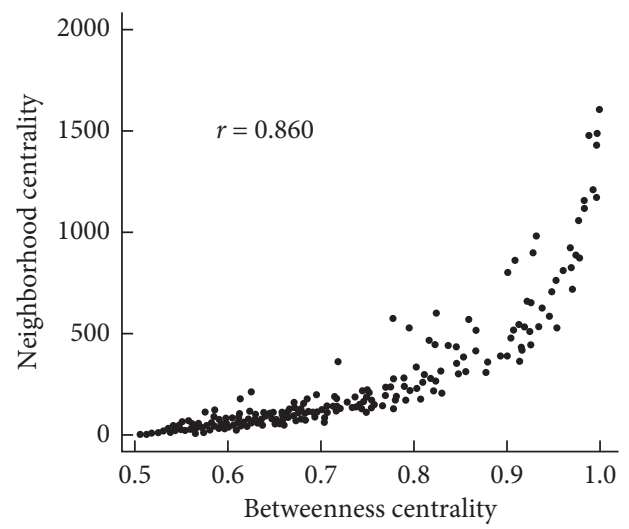

(f)

FIgURE 6: Correlation analysis of urban networks in China in 2019.

level aggregation. In contrast, as it was connected to a large number of low-degree nodes, the agglomeration of highdegree nodes was weakened [27]. The fitting results show that the cluster-degree correlation of China's urban networks was $\mathrm{C}(\mathrm{k}) \sim \mathrm{k}^{-0.1835}$, the power value was less than 1 , and the hierarchy of the whole network was not obvious, confirmed by the "long-tail" feature of the degree distribution already noted. On the whole, China's urban networks had a small number of core nodes but large degree values. Most nodes were of a small degree.

Degree had a significant positive correlation with betweenness centrality and neighborhood centrality, with correlation coefficients of 0.838 and 0.974 , respectively (Figures 6(d) and 6(e)). Betweenness centrality and 
neighborhood centrality also had a significant positive correlation, with a correlation coefficient of 0.860 (Figure 6(f)). This shows that with increasing node degree, betweenness centrality and neighborhood centrality increased. Moreover, a higher neighborhood centrality gave rise to higher betweenness centrality. Cities with more headquarter-branches and more investment activity had a larger centrality, equating to a higher status and stronger influence over the networks. These core cities are closer to other nodes, ensuring their functions of "broker" and "transfer" can be better fulfilled.

\section{Conclusion and Discussion}

From the perspective of "space of flows," flow-based data were used to measure the enterprise linkages of 353 cities in China from 1978 to 2019. We constructed directed and weighted urban networks for China and investigated their spatiotemporal evolution and complexity characteristics. The main conclusions are as follows:

(1) Intercity enterprise linkages in China have been continuously strengthened from 1978 to 2019 . The scale and density of urban networks have increased rapidly. At the same time, the distribution of importance and influence of node cities has been significantly unbalanced but has become more balanced over time.

(2) The diamond structure was the core of China's urban networks from 1978 to 2019. Urban networks were sparse in 1978, and enterprise flows were restricted by distance attenuation. Network density then significantly increased, forming a monocentric (Beijing) radial pattern. Since the beginning of the twenty-first century, the status of core nodes, e.g., Shanghai, has gradually become prominent. In 2019, four vertices stood out, composing a stable diamond structure. The spatial flows of enterprises constituted core networks with Beijing as the center, skeleton networks with trunk lines of subnodes, and the regional networks covering a wide range of peripheral areas.

(3) Complexity analysis shows that China's urban networks were typically small-scale and scale-free. However, the scale-free characteristics of China's urban networks became weakened after 2010. The overall scale gap of intercity enterprise linkages gradually narrowed, and the structure of urban networks became optimized. Meanwhile, China's urban networks featured as heterogeneous, without an obvious hierarchy. There were more cities with headquarter-branches and active investment behaviors. This imposed a strong influence on and control over networks, ensuring their functions of "broker" and "transfer" were fulfilled.

Using real flow-based data of enterprises to build a directed and weighted network can better reflect objective and realistic urban networks. By investigating a long time series, this article described and analyzed the topology, spatial structure evolution, and the complexity of China's urban networks. However, this work possesses several limitations: (1) The linkage strengths were calculated using an entropy method. Since this is an objective weighting method based on the dispersion of the data itself, an influence of data structure differences on the comparison results of each year cannot be ruled out. (2) Although the data obtained cover a wide range of years and cities, they only include the amount of investment and the number of branches of the whole industry and do not involve subindustry and specific category information of investment and branches. Thus, the analysis of different activity types and industries is restricted to a certain extent. (3) In this article, we focused on the topology, spatial structure, and complexity characteristics of China's urban networks in a long time series. The formation and evolution mechanism behind them is also worth discussion in the future.

\section{Data Availability}

Data of registered enterprises in China that we used to support the findings were supplied by State Administration for Industry and Commerce of People's Republic of China under license, which cannot be made freely available.

\section{Conflicts of Interest}

The authors declare that they have no conflicts of interest.

\section{Acknowledgments}

This study was supported by the National Natural Science Foundation of China (Grant no. 41971162).

\section{References}

[1] P. M. Hohenberg and L. H. Lees, The Making of Urban Europe, 1000-1994, Harvard University Press, Cambridge, MA, USA, 1985.

[2] P. Dicken, Global Shift: Mapping the Changing Contours of the World Economy, Sage, London, UK, 2007.

[3] J. Lu, D. Sun, J. Yu, J. Li, and F. Niu, "“Local versus nonlocal” enterprise linkages of global cities: a comparison between beijing and Shanghai, China," Complexity, vol. 2020, Article ID 8918534, 13 pages, 2020.

[4] S. Sassen, The Global City, Princeton University Press, New York, NY, USA, 1991.

[5] M. Castells, The Rise of the Network Society, Blackwell, Oxford, UK, 1996.

[6] B. Derudder and P. J. Taylor, "Central flow theory: comparative connectivities in the world-city network," Regional Studies, vol. 52, no. 8, pp. 1029-1040, 2018.

[7] J. V. Beaverstock, R. G. Smith, P. J. Taylor, and J. Taylor, "World-city network: a new metageography?" Annals Of the Association Of American Geographers, vol. 90, no. 1, pp. 123-134, 2000

[8] F. Pan, "Mapping urban networks through inter-firm service relationships: the case of China," Urban Studies, vol. 54, no. 16, pp. 3639-3654, 2017. 
[9] R. Capello, "The city network paradigm: theory and empirical evidence," Contributions to Economic Analysis, vol. 266, pp. 495-529, 2004.

[10] P. Hall, The World Cities, Heinemann, London, UK, 1966.

[11] J. Friedmann, "The world city hypothesis," Development and Change, vol. 17, no. 1, pp. 69-83, 1986.

[12] M. Castells, The Information City, Basil Blackwell, Oxford, UK, 1989.

[13] M. Castells, The Space of Flows, vol. 1, pp. 376-482, Blackwell, Oxford, UK, 1996.

[14] P. J. Taylor, "Specification of the world city network," Geographical Analysis, vol. 33, no. 2, pp. 181-194, 2001.

[15] Z. L. Tang, T. Li, and C. Li, "Research on the interlocking network of major cities in China," City Planning Review, vol. 41, no. 1, pp. 28-39+82, 2017.

[16] R. Capello, "The city network paradigm: measuring urban network externalities," Urban Studies, vol. 37, no. 11, pp. 1925-1945, 2000.

[17] B. Derudder, "On conceptual confusion in empirical analyses of a transnational urban network," Urban Studies, vol. 43, no. 11, pp. 2027-2046, 2006.

[18] P. J. Taylor, M. Hoyler, and R. Verbruggen, "External urban relational process: introducing central flow theory to complement central place theory," Urban Studies, vol. 47, no. 13, pp. 2803-2818, 2010.

[19] G. L. Xi, F. Zhen, J. L. He, and Y. H. Gong, "City networks of online commodity services in China: empirical analysis of tmall clothing and electronic retailers," Chinese Geographical Science, vol. 28, no. 2, pp. 231-246, 2018.

[20] J. Huang, D. Levinson, and J. Wang, "Tracking job and housing dynamics with smartcard data," Proceedings of the National Academy of Sciences, vol. 115, no. 50, 2018.

[21] M. X. Zhao, B. Derudder, and J. Huang, "Examining the transition processes in the Pearl River Delta polycentric megacity region through the lens of corporate networks," Cities, vol. 60 , pp. 147-155, 2017.

[22] R. Wall, "Corporate profiles and networks of gulf cities," $\mathrm{Al}$ Manakh, vol. 2, 2010.

[23] P. J. Taylor and D. R. F. Walker, "World cities: a first multivariate analysis of their service complexes," Urban Studies, vol. 38, no. 1, pp. 23-47, 2001.

[24] P. J. Taylor, World-city Network: A Global Urban Analysis, Routledge, London, UK, 2004.

[25] D. Bassens, B. Derudder, and F. Witlox, "Setting Shari'a standards: on the role, power and spatialities of interlocking Shari'a boards in Islamic financial services," Geoforum, vol. 42, no. 1, pp. 94-103, 2011.

[26] M. Hoyler, "External relations of German cities through intrafirm networks-A global perspective," Raumforschung Und Raumordnung-Spatial Research And Planning, vol. 69, no. 3, pp. 147-159, 2011.

[27] K. Wu, C. L. Fang, and M. X. Zhao, "The spatial organization and structure complexity of Chinese intercity networks," Geographical Research, vol. 34, no. 4, pp. 711-728, 2015.

[28] Z. Cao and B. Z. Peng, "Comparing the physical, functional and knowledge integration of the Yangtze River Delta cityregion through the lens of inter-city networks," Cities, vol. 82, pp. 119-126, 2018.

[29] M. X. Zhao, B. Derudder, and J. H. Huang, "Polycentric development in China's mega-city regions, 2001-08: a comparison of the Yangtze and Pearl River Deltas," DIE ERDE, vol. 148, no. 1, pp. 1-13, 2017.

[30] X. Wang, Z. D. Luo, and C. S. Zhu, "Dialectics of the center and the hinterland: a comparative study on regional spatial relations between Suzhou and ningbo based on corporation relation," Urban Planning Forum, vol. 5, pp. 79-85, 2014.

[31] B. Derudder, M. Hoyler, P. J. Taylor et al., International Handbook of Globalization and World Cities, Edward Elgar Publishing, Cheltenham, UK, 2012.

[32] P. Hall and K. Hall, The Polycentric Metropolis - Learning from Mega-City Regions in Europe, Earthscan, London, UK, 2006.

[33] B. Derudder, Z. Cao, X. J. Liu et al., "Changing connectivities of Chinese cities in the world city network," Chinese Geographical Science, vol. 28, no. 2, pp. 183-201, 2018.

[34] Z. P. Neal, B. Derudder, and P. J. Taylor, "Should I stay or should I go: predicting advanced producer services firm expansion and contraction," International Regional Science Review, vol. 42, no. 2, pp. 207-229, 2019.

[35] R. S. Wall and G. A. van der Knaap, "Sectoral differentiation and network structure within contemporary worldwide corporate networks," Economic Geography, vol. 87, no. 3, pp. 267-308, 2011.

[36] S. Kratke, "Network analysis of production clusters: the Potsdam/Babelsberg film industry as an example," European Planning Studies, vol. 10, no. 1, pp. 27-54, 2002.

[37] A. S. Alderson and J. Beckfield, "Power and position in the world city system," American Journal of Sociology, vol. 109, no. 4, pp. 811-851, 2004.

[38] W. K. Carroll, "Global cities in the global corporate network," Environment And Planning A-Economy And Space, vol. 39, no. 10, pp. 2297-2323, 2007.

[39] F. H. Pan, W. K. Bi, X. J. Liu, and T. Sigler, "Exploring financial centre networks through inter-urban collaboration in high-end financial transactions in China," Regional Studies, vol. 54, no. 2, pp. 162-172, 2020.

[40] P. J. Taylor, "Cities in globalization: practices, policies and theories," Applied Cognitive Psychology, vol. 2, no. 2, pp. 1$334,2007$.

[41] J. T. Song and C. L. Gu, "The theory and method of urban system planning," Journal of Geography, vol. 2, 1988.

[42] Q. Zhang and J. Liu, "The relationship between urban system planning reform and innovation and "three regulations in one"-from "three structures and one network", Urban Planning, vol. 38, no. 10, pp. 13-27, 2014.

[43] D. D. Lu, "Macro strategy of regional development in China," Journal of Geography, vol. 2, 1987.

[44] D. D. Lu, Location Theory and Regional Research Methods, Science Press, "Beijing, China, 1988.

[45] D. D. Lu, “"On the best structure and development of the region - review and reanalysis since the "point-axis system" and " $T$ " structure were put forward," Journal of Geography, vol. 2, 2001.

[46] L. Zhou, X. W. Dang, H. W. Mu, B. Wang, and S. H. Wang, "Cities are going uphill: slope gradient analysis of urban expansion and its driving factors in China," Science of the Total Environment, vol. 775, pp. 1-10, 2020.

[47] L. Zhou, X. W. Dang, Q. K. Sun, and S. H. Wang, "Multiscenario simulation of urban land change in Shanghai by random forest and CA-Markov model," Sustainable Cities and Society, vol. 55, pp. 1-10, 2020.

[48] C. Bao and X. J. Chen, "Review and prospect of research on spatial pattern of urban system in China," Advances in Geographical Sciences, vol. 33, no. 10, pp. 1300-1311, 2014.

[49] Y. Sun, L. C. Zhang, and S. M. Yao, "Spatial structure of urban network in China based on the headquarters and branches of express enterprises," Journal of University of Chinese Academy of Sciences, vol. 34, no. 5, pp. 91-597, 2017. 
[50] Y. R. Wang and R. X. Gu, “The spatial structure and evolution of Yangtze River Delta urban network: analysis based on enterprise connection," Urban Studies, vol. 26, no. 6, pp. 21-29+78, 2019.

[51] X. Jin, G. J. Hu, H. L. Ding, S. L. Ye, Y. Q. Lu, and J. H. Lin, "Evolution of spatial structure patterns of city networks in the Yangtze River Economic Belt from the perspective of corporate pledge linkage," Growth And Change, vol. 51, no. 2, pp. 833-851, 2020.

[52] Y. Li and N. A. Phelps, "Megalopolitan glocalization: the evolving relational economic geography of intercity knowledge linkages within and beyond China's Yangtze River Delta region, 2004-2014," Urban Geography, vol. 40, no. 9, pp. 1310-1334, 2019.

[53] H. M. Zong and R. H. Lyu, "The spatial characteristics and evolution of Chinese urban network based on logistics enterprise data in 2007-2017," Scientia GeographicaSinica, vol. 40, no. 5, pp. 760-767, 2020.

[54] B. R. Leng, Y. C. Yang, H. Xing et al., "The complexity analysis of urban network structure in China since 1990s based on gravity method," Regional Research and Development, vol. 5, pp. 68-73, 2011.

[55] Y. Dong, J. Luo, W. S. Zheng et al., "The urban network structure and complexity in hubei province," Economic Geography, vol. 7, pp. 76-84, 2019.

[56] G. Xian, G. Zeng, and X. Z. Cao, "Structural feature and proximity mechanism of Chinese intercity innovation network," World Regional Studies, vol. 27, no. 5, pp. 136-146, 2018.

[57] B. Derudder and P. Taylor, "The cliquishness of world cities," Global Networks-A Journal Of Transnational Affairs, vol. 1, pp. 71-91, 2005.

[58] P. J. Taylor, B. Derudder, M. Hoyler, and P. F. Ni, "New regional geographies of the world as practised by leading advanced producer service firms in 2010," Transactions Of the Institute Of British Geographers, vol. 38, no. 3, pp. 497-511, 2013.

[59] C. Rozenblat, "Opening the black box of agglomeration economies for measuring cities' competitiveness through international firm networks," Urban Studies, vol. 47, no. 13, pp. 2841-2865, 2010.

[60] L. Resmini, "Cities in globalization: practices, policies and theories," Journal of Regional Science, vol. 49, no. 1, pp. 228-230, 2009.

[61] C. Q. Nie, Study on Urban Network Spatial Structure Evolution of the Fan-Yangtze River Delta Based on the Corporate Organization Network, East China Normal University, Shanghai, China, 2018.

[62] L. Yi, "E-commerce and Enterprises' Trans-provincial Investment-Imperial Research of Chinese Listened Companies," Nanjing University, Nanjing, China, 2017.

[63] Z. R. Li, F. Zhen, and H. H. Fu, "Mapping urban network through inter-firm investment relationship: a case study of Yangtze River Delta," Scientia GeographicaSinica, vol. 39, no. 11, pp. 1763-1770, 2019.

[64] Y. D. Wei, "Decentralization, marketization, and globalization: the triple processes underlying regional development in China," Asian Geographer, vol. 20, pp. 7-23, 2001.

[65] K. Huang, G. Tian, and Y. Wang, "Tackle China's economic complexities by deepening reform and opening up: macroeconomic outlook, policy simulations, and reform implementation: a summary of the annual SUFE macroeconomic report (2018-2019)," Frontiers of Economics in China, vol. 14, 2019.
[66] K. H. Zhang, Q. L. Qian, and Q. S. Yang, "Analysis of multilevel influencing factors of urbanization of urban land in China," Journal of Geography, vol. 75, no. 1, pp. 179-193, 2020.

[67] J. Li and J. H. Long, "Research on the precise subsidy education model based on big data analysis," Information and Computer (Theoretical Edition), vol. 5, pp. 166-168, 2019.

[68] Y. Wang, W. Zhouhao, and C. Li, "The complexity of largescale urban networks: a comparative study in china," Transportation Research Board Annual Meeting, 2015.

[69] W. Liu, Q. Hou, Z. Xie et al., "Urban network and regions in China: an analysis of daily migration with complex networks model," Sustainability, vol. 12, 2020.

[70] S. Boccaletti, V. Latorabc, Y. Morenode, M. Chavezf, and D.-U. Hwanga, "Complex networks: structure and dynamics," Physics Reports-Review Section of Physics Letters, vol. 424, pp. 175-308, 2006.

[71] M. E. J. Newman, Networks: An Introduction, Oxford University Press, Oxford, UK, 2010.

[72] D. J. Watts and S. H. Strogatz, "Collective dynamics of 'smallworld' networks,” Nature, vol. 393, no. 6684, pp. 440-442, 1998.

[73] X. G. Ma and Y. Lu, "Spatial structure and connection of cities in China based on air passenger transport flow," Economic Geography, vol. 38, no. 8, pp. 47-57, 2018.

[74] X. Zhang, F. Z. Yu, and L. J. Xu, "Spatial structure of urban networks in China based on the perspective of cultural industry enterprise networks," Progress in Geography, vol. 39, no. 1 , pp. 78-90, 2020.

[75] B. X. Li, "Some thoughts on the development strategy and policy of southwest china," Review of Economic Research, vol. z2, pp. 1264-1274, 1993.

[76] M. Newman and M. Girvan, "Mixing patterns and community structure in networks," Statistical Mechanics Of Complex Networks, vol. 625, 1970. 